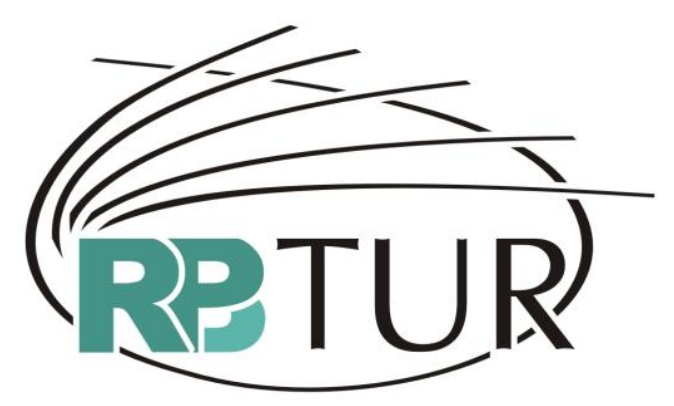

REVISTA BRASILEIRA DE PESQUISA EM TURISMO

\title{
ENSINO-APRENDIZAGEM EM UM CURSO DE HOTELARIA DA CIDADE DE SÃO PAULO: PERCEPÇÕES DE ALUNOS EM UMA NOVA ABORDAGEM DE ANÁLISE ${ }^{1}$
}

\author{
TEACHING AND LEARNING IN A HOSPITALITY PROGRAMME \\ AT SÃO PAULO CITY: PERCEPTIONS OF STUDENTS IN A NEW \\ ANALYSIS APPROACH
}

\section{ENSEÑAR Y APRENDER EN UN CURSO DE HOTELERÍA DE LA CIUDAD DE SAN PABLO: LAS PERCEPCIONES DE LOS ESTUDIANTES EN UN NUEVO ENFOQUE DE ANÁLISIS}

\author{
Airton José Cavenaghi ${ }^{2}$ \\ Karin Decker ${ }^{3}$ \\ Roberta Leme Sogayar ${ }^{4}$ \\ Roseane Barcellos Marques Sousa ${ }^{5}$ \\ Thaís Funcia ${ }^{6}$
}

\begin{abstract}
Resumo: Pesquisa exploratória sobre o processo de ensino-aprendizagem com o objetivo de identificar a natureza do ensino superior no contexto de uma sala de aula monocultural, como parte de um estudo mais amplo envolvendo ambientes multiculturais no Instituto de Educação Superior de Glion (Suíça). Com base em fundamentos teóricos do sense making, e a partir de observações em salas de aula e grupos focais com alunos do curso de Hotelaria da Universidade Anhembi Morumbi, descreve e analisa os resultados em cinco categorias interpretativas: vocação profissional, experiência de mercado, estratégias de ensino, aprendizagem e processo,

${ }^{1}$ Trabalho apresentado no VI Seminário da Associação Brasileira de Pesquisa e Pós-graduação em Turismo - ANPTUR 2009.

2 Doutor em História Social (FFLCH-USP); Professor Pesquisador do Mestrado em Hospitalidade (UAM-SP). Email: acavenaghi@gmail.com

${ }^{3}$ Mestre em Ciências da Comunicação (ECA-USP). Email: kdecker@anhembi.br

${ }^{4}$ Mestre em Administração de Turismo, Parques e Lazer (Western Illinois University) e Mestre em Hospitalidade (UAM-SP). Email: rosogayar@hotmail.com

${ }^{5}$ Mestre em Economia Política PUC-SP. Email: roseanebmarques@yahoo.com.br

${ }^{6}$ Mestre em Hospitalidade (UAM-SP). Email: funcia@anhembi.br
\end{abstract}


e vínculo. Destaca que os alunos questionam a ação pedagógica do professor de forma atuante e crítica. Conclui que se evidencia maior maturidade dos alunos em relação à figura do professor e as expectativas geradas por este processo.

Palavras-chave: Hotelaria. Educação. Aprendizagem multicultural. Aprendizagem monocultural. Ensino superior. São Paulo (SP). Brasil.

Abstract: Exploratory research on teaching-learning process aiming to identify the nature of higher education in the context of a monocultural classroom as part of a larger study conducted in Glion Institute of Higher Education (Switzerland) involving multicultural environments. Based on theoretical underpinnings of sense making, classroom observations and focus groups with hospitality students of Anhembi Morumbi University, this article describes and analyses the results of five interpretative categories: professional vocation, market experience, teaching strategies, learning process and bonding. It emphasizes that students question the teacher's pedagogical action in an active and critical way. It is concluded that more maturity towards the teacher's role and the expectations generated by this process is on evidence.

Keywords: Hospitality. Education. Multicultural learning. Monocultural learning. Higher education. São Paulo (SP). Brazil.

Resumen: Investigación exploratoria sobre el proceso de enseñanza-aprendizaje, con el fin de identificar la naturaleza de la educación superior en el contexto de un aula monocultural como parte de un estudio más amplio de entornos multiculturales, en el Instituto de Educación de Glion (Suiza). Sobre la base de los fundamentos teóricos de "dar sentido", y de observaciones de las clases y grupos específicos con estudiantes de Hotelería de la Universidad Anhembi Morumbi. Describe y analiza los resultados en cinco categorías de interpretación: la vocación profesional, experiencia en el mercado, las estrategias de enseñanza y aprendizaje, y la vinculación. Hace hincapié en que los estudiantes cuestionan la acción pedagógica del profesor y la forma activa de la crítica. Concluye con la evidencia de que los estudiantes más maduros en relación con la figura del profesor y con las expectativas generadas por este proceso.

Palabras clave: Hotelería. Educación. Aprendizaje multicultural. Aprendizaje monocultural. Educación superior. São Paulo (SP). Brasil.

\section{Introdução}

O presente estudo visa relatar elementos de uma pesquisa desenvolvida entre 2009 e 2010 com enfoque nas áreas de educação e hospitalidade. A pesquisa, iniciada com o apoio do Prêmio David Wilson atribuído pela Laureate International Universities - rede internacional de universidade presente em 17 países - em julho de 2008, baseia-se no estudo de modelos comparativos do processo de ensino-aprendizagem e enfoca a atuação do professor entre duas instituições da rede Laureate: Glion Institute of Higher Education na Suíça e a Universidade Anhembi Morumbi no Brasil. O estudo ainda busca comparar os 
ISSN: $1982-6125$

ambientes de sala de aula multicultural, sendo este em Glion, e um ambiente monocultural, na Universidade Anhembi Morumbi.

Na fase exploratória da pesquisa realizada no Brasil, seu objetivo foi o de identificar a natureza do ensino superior no contexto de uma sala de aula monocultural, como base para a posterior comparação com o estudo realizado em Glion, para averiguar a existência de modelos similares e distintos entre si. Preliminarmente foram realizadas quatro observações e entrevistas com professores do curso de Hotelaria de idades semelhantes, embora com caminhos profissionais diferenciados e área de atuação distinta. A partir disso, deu-se inicio à segunda etapa da pesquisa que contemplou a continuidade de observações in loco de aulas dos mesmos professores e seus objetos de estudo, e a realização de cinco grupos focais com alunos do próprio curso. A ideia de grupo focal encontra-se em sugerir ao entrevistado questões abertas com as quais teoricamente será possível resgatar respostas espontâneas e mais fidedignas.

Este trabalho refere-se a esta segunda fase e se inicia pelos fundamentos teóricos do sense making em ambientes culturais, e pela explicitação da metodologia adotada na mesma. Em seguida descreve e analisa os resultados obtidos a partir das seguintes categorias: vocação profissional, experiência de mercado, estratégias de ensino, aprendizagem e processo, e vínculo.

\section{Fundamentos Teóricos}

A compreensão da idéia de cultura passa pelas possíveis analogias que a mente do indivíduo produz com as realidades tangíveis e intangíveis, propostas pelo meio ambiente. Nesse processo é identificado um sistema de conduta, ou seja, atos e pensamentos individuais só são possíveis pela aprovação do todo, da memória coletiva atestada e gerida pelo grupo social do qual faz parte o indivíduo. Durham (1986, p.11), ao analisar a obra geral do antropólogo Malinowski, argumenta que "a noção de que a realidade social só pode ser 
apreendida enquanto sistema constitui a base e a origem dos conceitos de totalidade, de integração e de inter-relação funcional na análise da cultura".

A percepção do conjunto estrutural da aprendizagem é proposta pela observação e ajuda dos elementos externos, ou seja, os pares sociais, aqueles encarregados pelo grupo a servirem de condutores do processo de inserção do indivíduo aos espaços de aceitação e atuação desta memória coletiva. Instituições, tais como família, escola, trabalho, são modelos tradicionais nestes sistemas de condução da aprendizagem.

A abordagem conceitual adotada neste trabalho segue os estudos teóricos e analíticos sobre o sense making em Charlesworth (2008, p.48), para quem, em um contexto educacional, o resultado do processo de sense making é:

\begin{abstract}
Uma unidade de significado de dois elementos conectados. O conceito que prática e crença são interligadas é levado para sala de aula. Um professor que tenta com sucesso uma nova intervenção na crença de que irá contribuir para o aprendizado do aluno está no mesmo lugar em termos de sense making como um professor que descobre por acaso uma nova ação que resultou no processo de aprendizado e desenvolve uma crença na eficácia da intervenção. O sense making então, é um processo que ocorre quando um indivíduo usa meios racionais e conscientes para esclarecer as variáveis trazidas por novas situações. (Charlesworth, 2008, p.48; tradução dos autores).
\end{abstract}

As propriedades de sense making são descritas por Charlesworth (2008) ao citar que este é

\footnotetext{
"focado na construção de identidade de indivíduos, [...] sendo estabelecido em um ambiente sensorial, social, em andamento, [...] impulsionado por dicas extraídas do contexto, movido mais pela plausibilidade do que exatidão".
}

A autora aponta, corroborando a análise anterior de Durham (1986), que a resposta ao ambiente é um elemento que interfere diretamente na prática do ensino.

Charlesworth e Glanz (2008) representam graficamente a situação pedagógica da sala de aula multicultural por meio do modelo pinball de sense 
ISSN: $1982-6125$

making (figura 1), que mostra um processo no qual a bola $(A)$ representa a prática do ensino aplicada pelo professor. Nesse modelo, os cogs (B) (cavidades de pontuação) representam as estratégias de ensino utilizadas pelo docente. O objetivo do jogo é deixar a bola (informações transmitidas) em campo o mais tempo possível; quanto mais tempo em campo, maior a expertise do docente. Os flips (C) (abas impulsionadoras) representam um momento de surpresa que age como gatilho para o processo de sense making (D); representam um momento de oportunidade para voltar a bola em campo, e a volta da bola revela o input (retroalimentação) de sua ação em relação ao processo de sense making. O sistema ainda conta com uma "rota estéril (E), na qual o ensino continua em torno do jogo sem novos inputs que, desta forma, termina em oportunidades perdidas". (CHARLESWORTH, 2008, p.48).

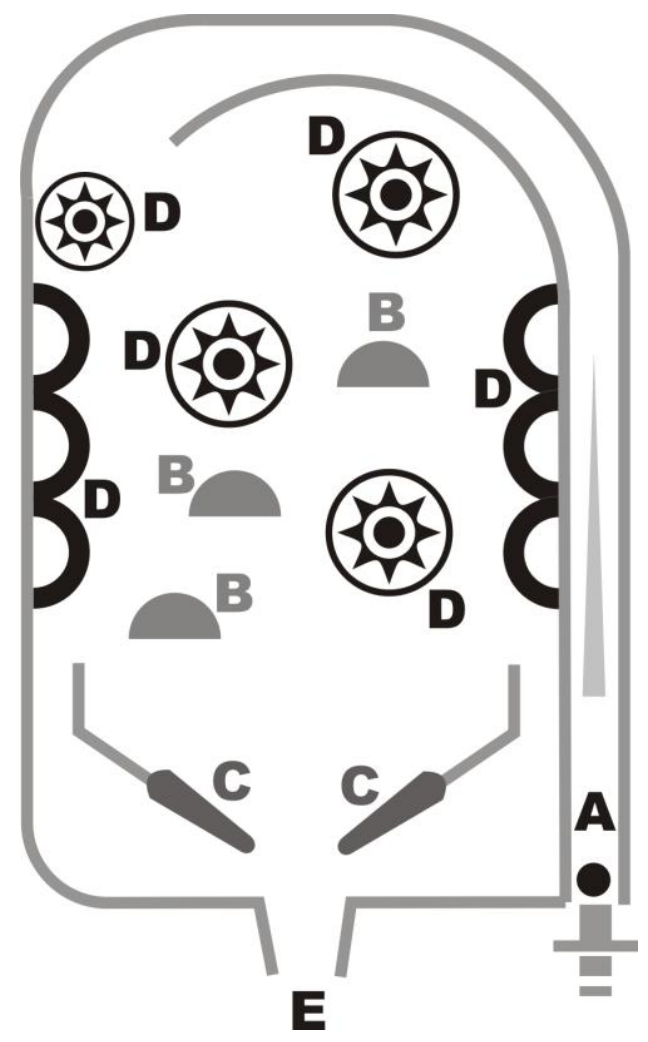

Figura 1 - Modelo pínball de sense making em sala de aula multicultural Fonte: adaptado de Charlesworth (2008, p.48).

Adler (1983) identifica algumas questões metodológicas que devem ser mencionadas neste estudo a fim de esclarecer a questão multicultural e 
monocultural. A autora aponta que se deve ter cuidado em equacionar nacionalidade com cultura, assumindo que as populações são culturalmente homogêneas, e deve ficar claro no estudo qual abordagem está sendo utilizada. Portanto é preciso enfatizar que para este estudo, os termos multicultural e monocultural não estão voltados à análise de cultura, mas sim a cultura está equacionada com nacionalidade. Nesse sentido o modelo aqui utilizado é local e pertinente aos problemas do grupo de sujeitos selecionados. A ampliação dos resultados coletados para a análise de outros grupos diferenciados ocorrerá na perda dos aspectos teóricos desenvolvidos pela pesquisa em andamento, ou seja, resultados não podem ser extrapolados para outros grupos de ensino superior sem conduzir uma pesquisa específica na cultura local em questão.

Trigwell e Prosser (1997, p.242) apontam que é o contexto que proporciona o desenvolvimento individual do aluno, contrapondo as duas visões citadas acima. Relatam a perspectiva constitucionalista, que difere das anteriores, fazem a distinção entre o mundo e o indivíduo, e enfatizam que "existe uma relação interna ao indivíduo e ao mundo", unindo ambos da seguinte maneira:

O indivíduo e o mundo não são constituídos independentes um do outro. Indivíduos e o mundo são internamente relacionados através da consciência dos indivíduos de mundo. A mente não existe independentemente do mundo à sua volta. O mundo é um mundo vivenciado. Não existe uma estrutura interna na mente que é composta de, ou que possa ser modelada em termos de partes independentemente constituídas (TRIGER; PROSSER, 1997, p. 242).

Desta forma os autores sustentam que em toda metodologia de ensino e aprendizagem, o processo de desenvolvimento do conhecimento encontra-se na percepção do mundo, leia-se meio ambiente, e de suas características cognitivas.

\section{Metodologia}


Foram realizados dois grupos focais com os alunos do quinto semestre do curso de Hotelaria da Universidade Anhembi Morumbi (São Paulo/SP). Para a montagem dos grupos, foi enviado um convite coletivo a todos os alunos do semestre em questão, via intranet, com um breve relato sobre o projeto de pesquisa em andamento. O convite assinalava para a participação do grupo focal em momento fora de sala de aula, sendo reforçado verbalmente pela coordenadora do curso de Hotelaria, pessoalmente, em sala de aula. Este fato possibilitou maior detalhamento e interação sobre o projeto aos alunos que, a partir desta ação, demonstraram-se interessados na participação.

Os critérios para a participação dos alunos no grupo considerou que estes deveriam ter o Certificado de Operações Hoteleiras de Glion obtido ao final do quarto semestre do curso. O Curso de Hotelaria da Universidade Anhembi Morumbi possui certificação internacional de Glion Institute of Higher Education e dupla titulação desde 2007. Ele é composto de créditos que os alunos do curso de Hotelaria devem cumprir ao longo dos primeiros quatro semestres juntamente com a aprovação em um exame de múltipla escolha em inglês, avaliando assim o desenvolvimento progressivo do aluno nos primeiros dois anos do curso.

Os grupos focais aconteceram no período matutino e noturno no Centro de Treinamento de Hotelaria, localizado nas dependências da Universidade. Do grupo focal I participaram três alunos, e do grupo focal II participaram dois alunos, cujos resultados foram gravados e transcritos pelos próprios professores pesquisadores. Os alunos participantes dos grupos focais assinaram um termo de anuência de participação e cessão de direitos da mesma para fins de produção de artigos e trabalhos acadêmicos.

Segundo Selltiz, (1975, p.295), a entrevista "focalizada" apresenta um método mais flexível, que permite a revelação de aspectos "afetivos e carregados de valor nas respostas das pessoas, bem como a significação pessoal de suas atitudes". O autor ainda acrescenta o caráter da espontaneidade, da revelação de informações pessoais, e da especificidade como o objetivo do método de grupo focal. Entretanto afirma que a liberdade 
do entrevistador pode ser um aspecto negativo, pois a flexibilidade do método "resulta em falta de comparabilidade de uma entrevista com a outra" (SELLTIZ, 1975, p.295).

O uso das técnicas de grupos focais também foi catalogado em recente estudo do Jornal of Sustainable Tourism como um dos instrumentos mais utilizados para a coleta de dados na atual produção científica deste caderno de Turismo (LU; NEPAL, 2009). A percepção da cultura como um suporte de pesquisa na área também vem sendo amplamente discutida por autores, que observam neste universo elementos reais para a percepção do fenômeno turístico (ver KRIPPENDORF, 2009).

As perguntas delimitadas para o grupo focal foram estabelecidas a partir dos objetivos do trabalho que serviram como uma estrutura para a condução do grupo. Segundo Selltiz (1975, p.295), o pesquisador "tem liberdade para explorar razões e motivos, indagar a respeito de direções que não foram previstas". Gaskell (2000, p.73) adiciona que as perguntas desenvolvidas para o grupo focal funcionam "quase que um convite ao entrevistado para falar longamente, com suas próprias palavras e com tempo para refletir".

O grupo focal, ainda de acordo com Gaskell (2000), denota uma interação social enfatizando o grupo e não o indivíduo, possibilitando o processo de observação de comportamento do grupo, incluindo a dinâmica da liderança e ainda a possibilidade da existência de envolvimento emocional, o que normalmente não ocorre em entrevistas individualizadas. As temáticas trabalhadas buscaram compreender a visão do aluno em relação à atuação do professor em sala de aula e a reflexão dos alunos no processo de aprendizagem e suas implicações. A análise das sessões foi organizada por conjunto de idéias posteriormente agrupadas em cinco categorias interpretativas, conforme explicitado no quadro 1 . Tais categorias surgiram das observações e análises dos resultados da pesquisa e são classificadas conforme o referencial teórico anteriormente explicitado (STERGIOU; AIREY; RILEY, 2008). 
ISSN: $1982-6125$

\begin{tabular}{|l|l|}
\hline \multicolumn{1}{|c|}{ Categorias } & \multicolumn{1}{|c|}{ Descrição } \\
\hline Vocação profissional & $\begin{array}{l}\text { Motivação interna; percepção da habilidade em } \\
\text { lidar com pessoas e ser professor. }\end{array}$ \\
\hline Experiência de mercado & $\begin{array}{l}\text { Problematização em sala de aula; capacidade de } \\
\text { tangibilização de assuntos teóricos e práticos; } \\
\text { valorização da experiência profissional do } \\
\text { professor; vivências internacionais possibilitando } \\
\text { reflexões globais. }\end{array}$ \\
\hline Estratégias de ensino & $\begin{array}{l}\text { Interação aluno-professor; recursos didáticos e } \\
\text { pedagógicos; promoção de análise de modelos } \\
\text { comparativos internacionais; gerenciamento do } \\
\text { ambiente de sala de aula para proporcionar um } \\
\text { aprendizado saudável; domínio do assunto. }\end{array}$ \\
\hline Aprendizagem e processo & \begin{tabular}{l} 
Definição do conceito. \\
\hline Vínculo
\end{tabular} \\
$\begin{array}{l}\text { Credibilidade e confiança; respeito; distinção do } \\
\text { professor pessoa e professor profissional em sala } \\
\text { de aula. }\end{array}$ \\
\hline
\end{tabular}

Quadro 1 - Categorias de análise da segunda fase da pesquisa

Fonte: os autores (2009)

\title{
Sensemaking em um ambiente monocultural
}

\author{
Vocação Profissional
}

Esta categoria relaciona-se à percepção do aluno do conceito de uma pessoa tornar-se um bom professor, ou seja, como é entendido este profissional no meio acadêmico e o que seria o fator principal para que uma pessoa busque a vivência nesta área de atuação.

Os alunos expressaram que a vocação profissional de um professor está atrelada a uma motivação interna e pessoal de cada um, que tem como objetivo a docência. Para eles a motivação está ligada à idéia de transmitir aos demais jovens, e futuros agentes de mudanças do mercado, seus conhecimentos; ter satisfação em fazer esse papel, e a busca de perpetuar seus conhecimentos e memórias. Com mais enfoque nas habilidades individuais do professor, os alunos colocaram a necessidade de relacionar-se com pessoas, de ter paciência e de estar aberto para a troca advinda de idéias 
ISSN: $1982-6125$

de outros. Neste caso, remete-se ao pensamento de Gasque e Tescarolo (2004), para quem

Os diferentes níveis de aprendizagem, portanto, estão relacionados com diferentes níveis de reflexão, e, quanto maior a capacidade de refletir, mais significativo e mais aprofundado será o pensar empregado na elaboração do conhecimento.

Experiência de Mercado

Esta categoria refere-se diretamente a uma questão de pré-requisitos. $\mathrm{Na}$ visão dos alunos, nota-se a idéia existente para um indivíduo tornar-se um bom professor, complementando-se, assim, a percepção da vocação profissional, já analisada anteriormente. A vivência profissional do docente é muito valorizada por ser fator fundamental no repertório de sala de aula do professor. Por meio de sua vivência profissional o professor tem maior capacidade de trazer fatos e casos para a sala de aula, problematizando periodicamente a cada situação estudada, e exemplificando-a com suas experiências passadas, relacionadas ao exercício da profissão. Por meio da exemplificação com casos reais, os alunos são capazes de tangibilizar assuntos teóricos, facilitando a aprendizagem dos conteúdos.

Outro ponto levantado pelos alunos está relacionado à vivência profissional do docente ter sido realizada também em ambientes internacionais. Além de toda a problematização e tangibilização que o professor possa utilizar, estas vivências permitem que este estimule as reflexões globais, de realidades localmente distintas. Como exemplo os alunos citaram um professor que após discorrer a teoria, finalizava o conteúdo com uma situação vivenciada ao longo de sua experiência profissional. Porém, além de citar e desenvolver o raciocínio focado na aplicabilidade teórica versus prática, o professor aprofundava o conteúdo ao utilizar a mesma situação exemplificada no caso anterior.

Essa vivência do professor permite que os alunos possam, além de assimilar de melhor forma os ensinamentos, desenvolver reflexões e análises 
ISSN: $1982-6125$

críticas no cenário global. O entendimento do cenário global pelo professor é muito valorizado pelo aluno. Por meio da experiência de mercado nota-se que este tema também é fator relacionado às estratégias de ensino e à questão do vínculo, como se vê a seguir.

\section{Estratégias de Ensino}

Nesta categoria reflete-se sobre como o aluno entende as "boas ferramentas" utilizadas por professores no ensino em sala de aula. Neste âmbito, a comunicação entre aluno e professor foi citada como o fator principal, sendo identificada por meio do reconhecimento da necessidade constante do professor em estar atento a um feedback da turma em relação ao processo de aprendizagem. Esta comunicação vem da interação alunoprofessor que deve ser realizada de forma constante, no simples fato do docente alocar minutos finais da sua aula para esclarecer dúvidas individuais ou gerais; pró-atividade do professor em buscar comentários dos alunos em relação à compreensão da matéria; ao iniciar as aulas buscando recapitular a aula anterior e ao final da aula fazer uma revisão da mesma. Em linhas gerais, tais ações estariam permitindo ao aluno compreender o ponto de partida e objetivo de cada aula, para com a disciplina e curso em si.

Os recursos didáticos e pedagógicos utilizados pelos professores não tiveram uma opinião única e fechada, pelo contrário, estiveram diretamente relacionados à área de conhecimento da matéria e essencialmente ao domínio do professor em relação à temática a ser trabalhada. Um dos exemplos citados foi na disciplina de Contabilidade, na qual o professor se utiliza somente de lousa e giz, caracterizando aulas predominantemente expositivas. Porém, a fixação do conteúdo se fez por meio de inúmeros exercícios e estímulos do professor à participação individual ou em grupo na solução de questões em sala de aula usando, inclusive, o próprio quadro negro; e ainda, mediante exemplos focados na área. Tais exemplos configuraram-se como elementos 
ISSN: $1982-6125$

facilitadores para uma melhor compreensão dos alunos acerca do conteúdo desenvolvido.

Por outro lado, os alunos observaram que não necessariamente uma disciplina externa à área das Ciências Humanas tem que ser ministrada sempre desta forma e com esta metodologia. Porém para os alunos do grupo focal este proporcionava boas aulas e seria um bom professor.

A utilização de recursos audiovisuais também foi muito considerada pelos alunos, pois diversificam as "ferramentas didáticas" utilizadas em sala de aula, tornando a aula mais dinâmica, e menos repetitiva ou exaustiva. Vídeos de propagandas comerciais, como também filmes em geral, são bem apreciados pelos alunos, sempre que esta ação seja um complemento aos aspectos teóricos, não devendo ser utilizados, pelo professor, na totalidade da aula.

Ainda segundo os alunos, os recursos de data-show e projeção de apresentações em slides (como os do software Power Point) devem ser observados com cautela pelos professores. Um dos exemplos citados foi à utilização de apresentações de slides por professores do período matutino, nos primeiros momentos das aulas, com as luzes apagadas, o que tornava 0 ambiente propício para a sonolência. Novamente as ferramentas não possuem, para os alunos, uma regra única e, neste caso, cabe ao professor a percepção de qual será a mais aplicável dentro das variantes de horários, ambientes e temáticas a serem abordadas.

Em relação à técnica de apresentação de seminários e o papel do aluno, este deve ser cada vez mais ativo na construção do seu próprio conhecimento, e o professor, um facilitador que também apresentará sua contribuição, não se colocando no centro do processo de aprendizagem. Os alunos perceberam esta necessidade, porém observaram que é oportuno e necessário um processo de mudança.

Para seminários, por exemplo, faz-se necessário que o professor detalhe os objetivos de cada projeto, e faça uma breve introdução do assunto a ser tratado. Tal ação irá garantir, aos alunos, segurança e confiança para o desenvolvimento do mesmo. Na apresentação dos seminários, é importante 
que o professor crie um ambiente de debates que possa sempre complementar as informações dos trabalhos apresentados, seja de forma positiva, ou recomendando maiores leituras a todos os alunos. A palavra do professor tem que ser a final para, desta forma, acentuar a credibilidade vinculada ao processo de ensino aprendizagem. Essa questão será retomada quando for analisado o vínculo aluno-professor.

Conforme citado na análise de experiência de mercado, a problematização e utilização de casos vivenciados pelo professor são ferramentas essenciais aos alunos. Dessa forma a análise de modelos comparativos internacionais também se torna importante, e é percebida como resultado da experiência de mercado dos docentes.

Os alunos finalizaram argumentando que $o$ fator predominante $e$ fundamental para uma boa aula é o ambiente da mesma. Todos os alunos concordaram que o gerenciamento de comportamento e atitude dos alunos por parte do professor é o elemento-chave para proporcionar um ambiente de aprendizagem saudável.

Aprendizagem e Processo

Nesta categoria tem-se a visão do aluno, quais seriam as definições de aprendizagem e de processo, destacadas nos seguintes depoimentos dos alunos:

[...] eu acho que você nunca aprende com o erro dos outros, então não adianta, não é que não adianta nada, eles dão dica, contam experiência assim, mas a gente nunca sabe o que vai acontecer com a gente, na hora, então a gente tem como base, a gente sabe, já escutou em algum lugar, mas você ta lá na pratica e aí você vai e faz e ai você fala putz se eu tivesse parado para pensar um segundo ....ai eu acho que entra a aprendizagem... você aprendeu mesmo [...] (Aluno 1).

[...] juntar a prática e o teórico [...] (Aluno 2).

[...] eu acho que é realmente quando você cria consciência a respeito daquilo no sentido que você pode usar aquela informação e aquele conhecimento para transformar e criar (Aluno 3). 
CAVENAGHI, Airton José, et al. Ensino-aprendizagem em um curso de hotelaria da cidade de São Paulo: percepções de alunos em uma nova abordagem de análise. Revista Brasileira de Pesquisa em Turismo. v.5, n.1, p.101-117, abr. 2011.

ISSN: $1982-6125$

[...] quando você é capaz de absorver as informações, absorver os conhecimentos, então ai você estaria aprendendo... então o processo de aprendizagem é desde as aulas, até o trabalho, até a ficha cai a vem a aprendizagem [...] (Aluno 4).

Percebe-se, pelos depoimentos acima, que os alunos apresentam uma percepção própria do processo de aprendizagem. Este fato é notado, por exemplo, na dispersão inicial observada principalmente na fala do Aluno 1.

Esta descrição pode ser comparada a "rota estéril" descrita anteriormente por Charlesworth (2008). A ação do professor estaria em indicar como a percepção de aprendizagem pode ser observada, pelo próprio aluno, na análise crítica do cotidiano das suas próprias atividades diárias.

\section{Vínculo}

Esta categoria - vínculo aluno-professor - não foi trabalhada de forma direta nas entrevistas dos grupos focais. Porém ao longo das respostas dos alunos em relação às demais questões colocadas, percebeu-se que esta podia ser como o vínculo criado no relacionamento entre professor e aluno em sala de aula.

Os alunos vêem na figura do professor uma posição de credibilidade e confiança. Colocam-no num patamar de respeito e de certa maneira, de idolatria. Desta forma os alunos apontaram que o domínio do assunto tratado e a motivação interna pessoal e experiência profissional são elementos essenciais para o bom desempenho do professor, e neste vínculo formado, criam-se as expectativas do aluno. A necessidade da realização de um feedback do professor para os alunos é muito evidenciada. O aluno prima por saber a opinião ou visão do professor, qual a avaliação e análise que ele faz em relação às inúmeras situações apresentadas: "A palavra final tem que vir do professor".

Demonstraram ainda maturidade em distinguir o relacionamento alunoprofessor e a diferença do professor como profissional e como indivíduo. Exemplificaram este fato com a exposição da imagem de um professor que, de 
ISSN: $1982-6125$

forma unânime, os alunos consideram ser ótima pessoa, porém como docente "deixa a desejar", por mais que tenha experiência de mercado internacional e motivação para ensinar.

Esta caracterização do "vínculo" já havia sido discutida anteriormente de forma mais ampla por Bordenave e Pereira (1988), para quem tanto o aluno quanto o professor devem ser vistos como "pessoas", ou seja, as características pessoais de cada aluno deve merecer atenção do professor, em virtude de afetarem significativamente o processo de aprendizagem. Aqui se percebe diretamente a idéia do "vínculo", processando-se como a identificação do aluno com a figura do professor. Considera-o como a "ponte" necessária à materialização direta do processo ensino-aprendizagem.

\section{Considerações Finais}

Com a análise desenvolvida das entrevistas dos grupos focais, torna-se evidente a maturidade e a presença de um maior critério dos alunos em relação à figura do professor e as expectativas geradas por este processo.

A prática docente não é uma técnica única e pré-formulada e que deve ser seguida em uma condição unilateral. Variáveis são constantes no processo de aprendizagem, e a classificação de bom professor e boa aula não possui uma resposta final única, nem tampouco atende a um perfil exclusivo de profissional. Porém de todas as respostas obtidas torna-se evidente que se o professor detém as características e experiências necessárias para uma boa aula, consolida-se, efetivamente, o processo de aprendizagem. Nota-se também, que o momento cotidiano dos alunos deve ser levado em consideração pelo professor no processo de construção do seu modelo de ensino-aprendizagem. Cada nova situação vivenciada pelo educando pode ser usada como uma plataforma de sustentação de novas idéias de ensino.

Um aspecto a ser destacado é que os alunos questionam a ação pedagógica do professor de forma atuante e crítica. Este fato corrobora a idéia que toda ação pedagógica do professor deve ser amparada em um 
planejamento didático não estanque ao programa de ensino previamente definido por ele. Cada professor deve pensar em possibilidades constantes, ou seja, nos "inputs" da analogia sugerida pelo modelo teórico de análise de "pinball".

Por fim assinala-se que por se tratar de uma pesquisa de caráter exploratório, seus resultados não podem ser generalizados, sendo portanto indicativos da realidade investigada. Porém, além de ter sido um exercício profícuo para os autores, testou e demonstrou a adequação da metodologia e pertinência da fundamentação teórica, imprescindíveis ao desenvolvimento da segunda fase da pesquisa.

\section{Referências}

ADLER, N. J.. A typology of management studies involving culture. Journal of International Business Studies, fall 1983, n.14, p.29-47.

BAUER, M.W.; GASKELL, G. (ed.). Pesquisa qualitativa com texto, imagem e som: um manual prático. 2.ed. Petrópolis: Vozes, 2002.

CAVENAGHI, A.; DECKER, K; FUNCIA, T.; SOGAYAR, R.; SOUSA, R.. Do ensino à aprendizagem: o desafio da sala de aula multicultural. In Anais do II Colóquio Internacional em Hospitalidade: rostos e lugares da hospitalidade. Porto: Universidade Católica Portuguesa, 2009.

. Do ensino a aprendizagem: um estudo exploratório sobre as percepções do ensino e aprendizagem de um curso de hotelaria da cidade de São Paulo. In VI Seminário ANPTUR: Turismo e Hospitalidades nas Pesquisas Científicas, 2009, São Paulo: ANPTUR, 2009.

CHARLESWORTH, Z. M.; GLANZ, L. From teaching to learning: the challenge of the international classroom for hospitality educators. In Council for hospitality management education. The Strathclyde University: Glasgow (Scotland), 2008. P. 14-16. (Artigo apresentado na conferência anual "Promovendo excelência na pesquisa, no ensino e no aprendizado")

CHARLESWORTH, Z. M.. Meeting the challenge of the international hospitality classroom. The Hospitality Review, 2008, v.5, n.10, p.47-51.

DIAS BORDENAVE, J.; PEREIRA, A. M.. Estratégias de ensino-aprendizagem. 10.ed. Petrópolis: Vozes, 1988.

DUHAM, E. R. (org.). Bronislaw Malinowski. São Paulo: Ática, 1986.

GASQUES, K. G. D.; TESCAROLO, R.. Sociedade da aprendizagem: informação, reflexão e ética. Ciência da Informação [online], set. 2004, v.33, n.3, p.35-40 Disponível em: <http://www.scielo.br/pdf/ci/v33n3/a05v33n3.pdf>. Acesso em 23 out. 2009.

KRIPPENDORF, J. Sociologia do turismo. 25.ed. São Paulo: Aleph, 2009. 
ISSN: $1982-6125$

LU,J.; NEPAL, K. S.. Susteinable tourism research: an analysis of paper publisher in the Journal of Sustainable Tourism. Journal of Sustainable Tourism, jan 2009, v.17, n.1, jan. 2009, p.5-16.

TRIGWELL, K.; PROSSER, M. Towards and understanding of individual acts of teaching and learning. Higher Education Research and Development, jun. 1997 , v.16, n.2, p.241-252.

SELLTIZ, et al. Métodos e técnicas nas relações sociais. 5.ed. São Paulo: EPUEDUSP, 1975.

STERGIOU, D.; AIREY, D.; RILEY, M.. Making sense of tourism. Annals of Tourism Research, jul. 2008, v.35, n.3, p.631-649.

Artigo recebido em dezembro de 2010.

Aprovado para publicação em fevereiro de 2011. 